\title{
Towards developing a model for the evaluation of hospital disaster resilience: a systematic review
}

\author{
Saeed Fallah-Aliabadi ${ }^{1}$, Abbas Ostadtaghizadeh ${ }^{1 *}$, Ali Ardalann ${ }^{1,2}$, Farin Fatemi ${ }^{3}$, Bijan Khazai ${ }^{4}$ and \\ Mohammad Reza Mirjalili5
}

\begin{abstract}
Background: Hospitals play a vital role in disaster stricken regions. The resilient hospitals will be able to provide essential services to affected people and it can mitigate the risk of injuries during and after disasters. This study aimed to obtain the indicators required for the evaluation of hospital resilience.

Methods: This systematic review was conducted in 2018. Through this systematic review, international electronic databases were investigated for the research studies published in English. The exclusion and inclusion criteria were determined to extract the hospital resilience indicators. These indicators will be used in order to develop a model to keep the system performance at an acceptable level during disasters.

Results: Out of 1794 research studies published until September 2018, 89 articles and guidelines with full text were surveyed. Thirty-two articles and guidelines were then selected and analyzed to collect the indicators related to hospital disaster resilience (HDR). The domains and the indicators were extracted from these selected research studies. The authors collected and categorized them into three domains and twenty seven subdomains. The three domains included constructive, infrastructural, and administrative resilience. The relevant indicators were designed for each subdomain to assess HDR.
\end{abstract}

Conclusion: Since diverse indicators affect hospital resilience, other studies should be conducted to propose some models or tools to quantify the hospital resilience in different countries and scopes with an all hazards approach.

Keywords: Disaster, Hospital, Resilience, Structural and non-structural systems, Indicators

\section{Background}

Natural and human made disasters impose different range of damages, injuries and death to affected communities [1]. These can disrupt infrastructures and facilities, such as hospitals, schools, transportation systems, and emergency services. When these disasters occur, damages can be related to physical components, such as building structure, construction materials, and non-structural systems like medical equipment, lifelines, and architectural features. Hospital staff could be affected during disasters and their

* Correspondence: ostadtaghizadeh@gmail.com

'Department of Health in Emergencies and Disasters, School of Public

Health, Tehran University of Medical Sciences, Tehran, Iran

Full list of author information is available at the end of the article absence or unpreparedness influences the service continuity at urgent situations induced by disasters. Therefore, it is supposed that they would be wellaware of their role in implementing disaster plans. In case of hospital structural and non-structural failures, large investment should be done for continuity of service delivery in open areas or temporary buildings. Moreover, the activities for repair or reconstruction should be performed [2-4]. The literature review indicates that the main reason for most of the damages in health facilities is related to inappropriate site selection for the building, lack of proper design or insufficient maintenance [5]. Recent disasters throughout the world resulted in hospital damages and interruption in medical services [6-10]. For instance, in August 2012 and during Varzaghan-Ahar twin 
earthquakes in Iran, the performance of both Heriss and Ahar hospitals were not satisfactory. There were huge damages to the columns and beams, false ceilings and walls. Due to the lack of safety inside these two hospitals, the medical services were performed outside zone at the temporary hospitals set up in the tents [11]. After the devastating earthquake in Ezgele, Kermanshah in the west side of Iran in November 2017, the newly-built Islamabad and Sar-e-Pol-e Zahab hospitals were subjected to structural and nonstructural damages which resulted in power outage and providing services outside the buildings [12]. The damages or malfunctioning of hospitals components in the case of emergencies and disasters will have direct or indirect impact on the continuity of medical services and result in more injuries or fatalities [13]. Therefore, it is important to encourage researchers, engineers and decision makers to develop ways to improve the resilience of healthcare facilities [14, 15].

In the world conference on disaster reduction in Hyogo, Japan, the aim of "hospitals safe from disaster" was proposed by ensuring that all new hospitals should be built with a level of resilience that strengthens their capacity to remain functional in disaster situations [16]. Also, during the third world conference held in Sendai-Japan, in 2015, the resilience of health infrastructures and disaster risk reduction measures were emphasized [17].

The systems resilience can be defined as containing four R that represents Robustness (inherent strength), Redundancy (replace ability of resources), Resourcefulness (having plans and strategies) and Rapidity (achieve priorities promptly) [18]. Ostadtaghizadeh et al., in a systematic review proposed a classification for community disaster resilience which included natural, economic, social, institutional, and infrastructural domains [19]. From the health aspect, the resilient system should be able to prepare for, withstand the stress of, and respond to the public health consequences of disasters successfully [20]. Hospital resilience is related to decreasing vulnerability to the shocks brought by disasters and increasing adaptive capacity brought by improved measures and opportunities [21].

There are significant amount of research conducted to understand hospitals response to hazards and some studies containing a tool or instrument like Hospital Safety Index (HSI) as a rapid, reliable, and cost-effective diagnostic tool for assessing the safety of hospital buildings, critical systems and equipment, the availability of supplies, and the emergency and disaster management capacities of the hospital. This tool not only helps to assess safety status, but also helps to evaluate the response capacity of the hospitals [22-27]. Moreover, there are some studies that mentioned instruments for assessing Hospital Disaster Resilience (HDR). In some of them the authors focused on operational characteristics of hospitals; however, the structural and non-structural aspects of hospital resilience were not mentioned in details [28-33]. For instance, Zhong proposed multiple concepts for assessing hospitals resilience in response to disasters in China. The variables used in this study included hospital safety, emergency services, surge capacity, command, disaster plan, logistics, staff ability, disaster training, communication and cooperation systems, recovery, and adaptation [34]. With regard to the importance of evaluating, monitoring, and planning in order to improve HDR, it is necessary to develop a validated model to evaluate HDR. To do so, it is required to identify all the factors and indicators mentioned in different studies and categorize them in a framework [33]. This study aimed to identify, collect, and categorize the factors that could be used for assessing HDR.

\section{Methods}

\section{Databases and search strategy}

This study as a systematic review covered the electronic academic resources, such as articles, books, documents, and reports published before September 1, 2018. There were no limitations with the type or the date of studies, but the study language was only restricted to English. International electronic databases, including Pubmed, Web of Science, Scopus, and Google scholar were investigated. In addition, the ProQuest Research Library which only contains thesis was searched too. The search key terms were selected from three major scopes after consulting with experts, hospital, disasters, and resilience. In addition to keywords provided by experts, to find more relevant citations, MeSH entry terms service of PubMed were used. The experts mainly were from scientific institutions and organizations which were involved in disaster risk reduction and disaster management and had some academic papers and also systematic review articles in this field. The search strategy was determined for searching the databases as follows:

(Disaster* OR emergency*) AND (resilience*) AND (hospital" OR healthcare OR health care). This strategy was applied in titles, abstracts, keywords in all databases. The complete search strings are included in Additional file 1.

\section{Inclusion and exclusion criteria}

Included documents were credible articles, guidelines, and grey literature written in English that focused on structural or non-structural systems of a hospital, such as buildings, lifeline or utility, including water, power, and fuel/gas/energy. Moreover, they had to explain or present the factors, indicators, variables, models or instruments that affected the resilience of the structural or non-structural systems of the hospital in case of 
disasters. The articles which were related to the individual, staff, psychological and economic resilience were excluded and also those which did not present the factors or indicators of HDR. The documents without full text or those which their full texts were not available were excluded. Table 1 shows the inclusion and exclusion criteria.

Figure 1 outlines the PRISMA flow diagram for the selection process in the studies for this review.

\section{Data extraction and analysis}

For extracting the data, two independent researchers performed the screening of the titles and abstracts to choose the relevant articles according to the inclusion and exclusion criteria. Then, the full texts of the total articles were reviewed. In the case of disagreements between two researchers at this stage, the third researcher joined the review team and helped them select the most relevant articles. Then, two forms were developed, one for importing general information from the selected articles by mentioning the names of the authors, type of articles, the research country, date of publication, methodology, and objective of the studies. Another form was applied for identifying the name of the models and tools, the details of domains and indicators and the factors mentioned in them.

\section{Results}

The initial search resulted in identification of 1794 potentially relevant documents from the four international databases (PubMed, Scopus, Web of Sciences and Google scholar), 612 literatures were duplicated and removed. The remained documents included 1182 studies, from which 746 were excluded after screening their titles and abstracts; since they did not include the determined inclusion criteria; while 436 papers were included. By investigating the abstracts in details, 347 studies were excluded because of having no domains or indicators of HDR. Then, 89 studies were selected for full text reading and 57 articles were excluded due to lack of enough information or suitable factors or indicators to assess HDR or the full texts were not accessible. Finally, full-text review of these articles led to 32 documents which were included in the present study. The study was developed based on the PRISMA checklist assessment tool.

\section{Descriptive analysis}

By reviewing the 32selected articles and guidelines published before September 1, 2018, it was obvious that the largest numbers of papers were from the United States (40\%), followed by the United Kingdom and Malaysia (10\%), Iran, China and Canada (7\%).Other research studies were from Colombia, Belgium, Italy, Japan, Switzerland, Australia, and New Zealand. These 32 final documents included original articles, guidelines, reviewed articles, and conference papers. It also showed that the focus on HDR has recently increased, so that more than 20 included articles in this systematic review have been published after 2014. Sixteen articles had the all-hazards approach and others (10 articles) discussed the seismic resilience of hospitals and six articles were related to climate change, including extreme weather events, hurricane or flood. Through surveying, the methodology of the articles and guidelines showed that only two articles were review research studies, four guidelines, and the remained articles were original research studies. Literature review was as a basic part of all of the articles. The methodology of these articles were divided into three types, including eight articles which used qualitative methods, 13articles used quantitative methods, and the methodology of the other nine papers were both qualitative and quantitative. The remained article was a narrative study. Additional file 2 shows the characteristics of the full sources included in the study $[4,8,25,27,29,31-33,35-58]$.

\section{Thematic analysis}

For extracting the domains, subdomains, and indicators related to HDR, all the 32 selected articles and guidelines were reviewed. From these studies, four research studies proposed a model, framework or tool which developed the process of assessing HDR. These model, tools, and framework were as follows: Hospital Safety Index (HSI) [27], Dynamic approach to the seismic resilience of hospitals [45], Measuring framework of the hospital resilience [33], and The indicators for assessing

Table 1 The inclusion and exclusion criteria for article selection

\begin{tabular}{ll}
\hline Inclusion Criteria & Articles, guidelines and grey literature written in English. \\
& The studies that focused on structural or non-structural systems of a hospital. \\
& The studies that present the factors, indicators, variables, models or instruments that affected the resilience of the structural \\
& or non-structural systems of the hospital. \\
Exclusion Criteria & The studies that relates to fields of resilience such as individual, staff, psychological and economic resilience. \\
& The articles that do not present the factors or indicators of HDR. \\
& The studies that we couldn't find their full text.
\end{tabular}




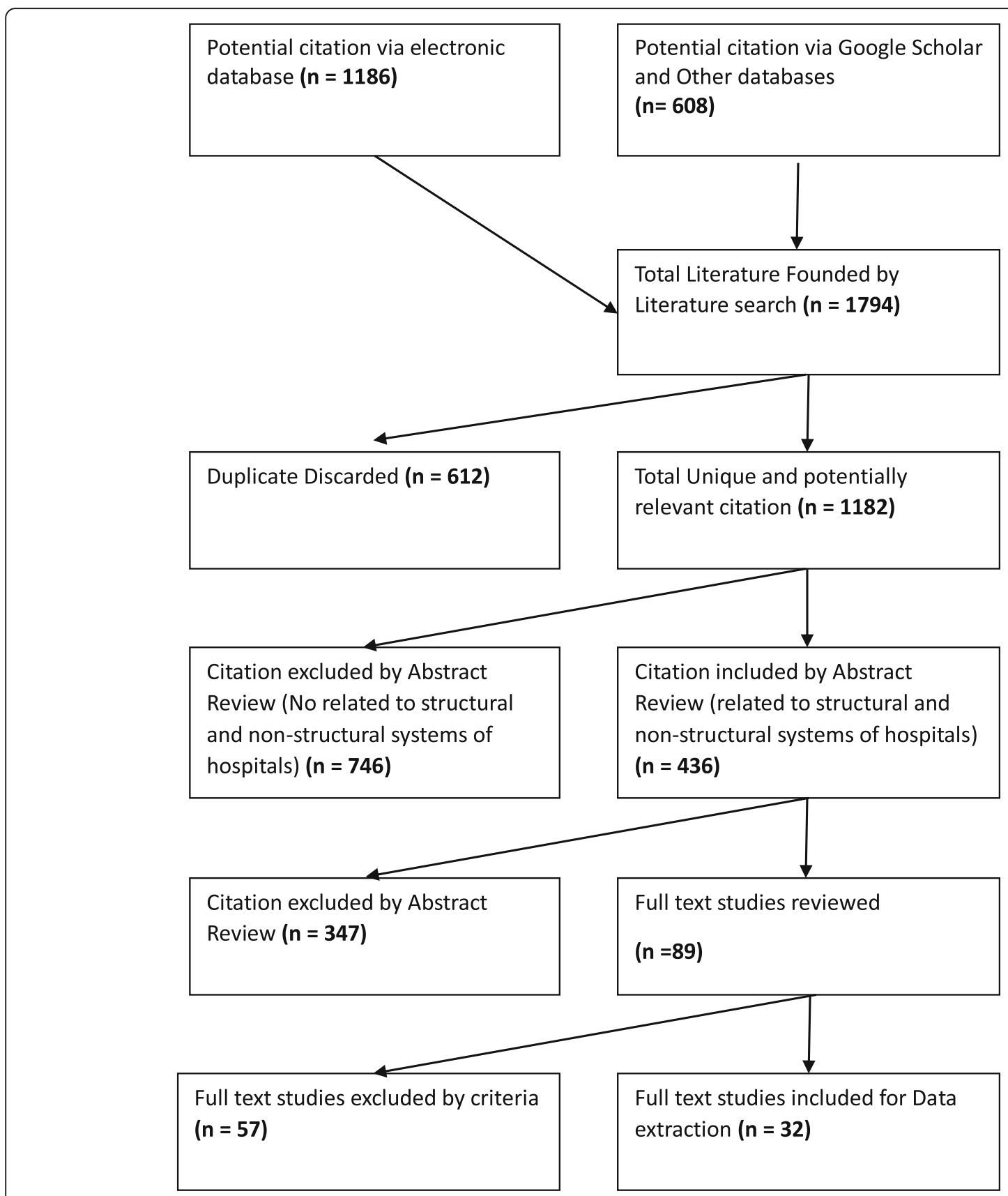

Fig. 1 Flow diagram of the search and selection of studies

hospital disaster preparedness in Japan [25]. Some of the articles did notpresent any tool or model for assessing HDR; however,they consisted relevant indicators or variables to HDR. Table 2 represents tools and models, as well as indicators for assessing HDR.

\section{Discussion}

This study aimed to determine the domains and indicators for assessing HDR through a systematic review. Given that the proper and timely operation of hospitals is crucial in times of crisis; their resilience needs to be addressed. Therefore, the comprehensive assessment of HDR helps to find the weaknesses and challenges in the scope of disaster risk and remove them to mitigate the harmful consequences of disasters [59]. The desirable performance of hospitals during and after disasters and their continuity to services depends on different factors, such as hospital building stability, including the structural and non-structural systems [60]. Several studies were carried out in different fields of HDR, such as 


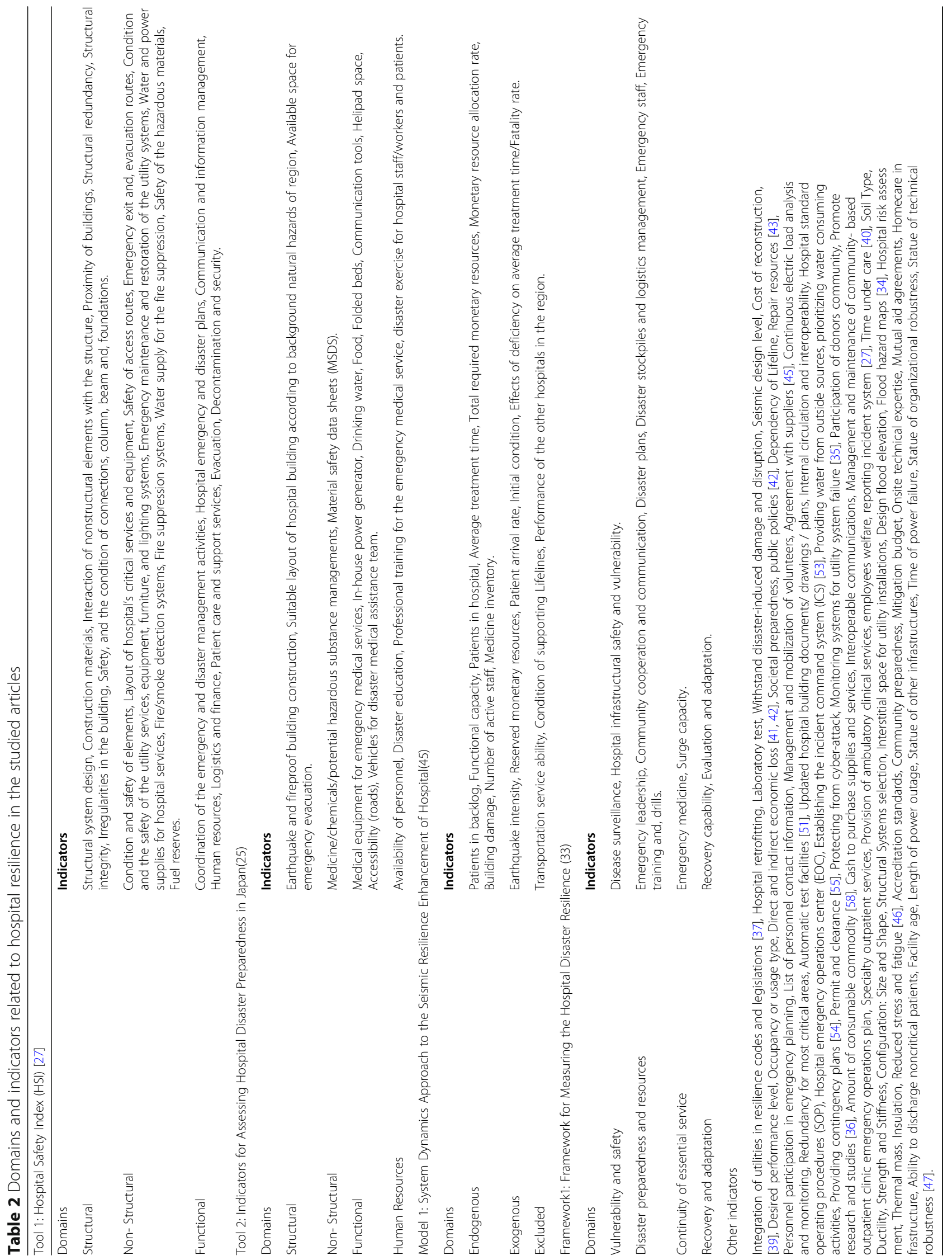


organizational resilience which is related to functional services of the hospital [1, 46, 61-63]. However, the studies which are substantially related to structural and non-structural components of hospitals have been rarely found. Thus, a systematic method of HDR regarding the structural and non-structural systems would be required. Some indicators which were directly related to medical services, such as triage or referral, transfer, and reception of patients excluded in the present review. However, the indicators that described the structural and nonstructural characteristics as well as administrative and functional activities concerning structural and nonstructural systems included in this study. Most of the studies focused more on electrical and water utilities and transportation networks in hospitals [40, 42, 46, 51, $53,54,56,58,64]$. The literature showed that other utilities in hospitals like communication system, gas supply system, sewage system as well as non-structural components of buildings, such as architectural elements have been less considered. In the case of healthcare facilities, nonstructural components often represented greater economic value rather than the structure itself. Analyses indicated that nonstructural components generally accounted for more than $80 \%$ of the total costs of a hospital [65]. Moreover, there is a crucial difference between risk reduction (safety and preparedness) and resilience in this regard. Safety is defined as "a state in which hazards and conditions leading to physical, psychological or material harm are controlled in order to preserve the health and well-being of individuals and the community" [66]. However, resilience is defined as a concept for the ability or capacity of a system or community to deal with risk [67]. Based on these definitions, it can be found that safety and risk reduction is mainly used to reduce the level of risk; however, resilience is used to keep control of the functionality of a system when the system is prone to risk. The model, tools, and framework in Table 2 had properties which helped to improve a model to assess HDR. The HSI tool and frameworks proposed by Zhong had an all-hazards approach [27, 33]. The HSI has three sections, including structural, non-structural and disaster management system [27]. The structural system refers to elements of building that withstand loads. Other elements of buildings, such as utilities and architectural systems are categorized as non-structural system. One of the advantages of this tool is that the non-structural section is wide and consists of many sub-categories. The disaster management category in HSI has emphasized on preparedness of the hospital system, including human resources readiness, preparing action plans, management of communication and information systems, patient care and support services, and logistics and finance. Another surveyed tool was presented by Mulyasari et al., including four domains and indicators for improving the resilience of hospitals against earthquakes in Japan [25]. Analyzing this tool demonstrates that the proposed approach is not comprehensive in spite of having four domains. Three domains similar to HSI modeland human resources were also added. This tool focuses mainly on the power and water systems and not structural condition of hospitals and other utilities. Moreover, the main focus of human resources domain is just on medical staff, so that the other groups of hospital staff have been neglected. The other disadvantage is that this tool considers only the preparedness phase, while a resilient hospital system should cover different phases of disaster management, including mitigation, preparedness, response, and recovery [68]. The model proposed by Khanmohammadi et al., concentrates on the hospital building and relevant technical services failure after earthquakes at the recovery phase in Iran. It cites the impacts of hospital damages and the resource shortage on the quality of services and uses the relevant variables to quantify the hospitals resilience [45]. The model variables were classified into three groups, including the endogenous, exogenous, and excluded variables. The endogenous variables can affect the building damages, the exogenous variables, including earthquake intensity, and the excluded variables that would help to quantify the functionality of the hospital.

Zhong suggested a framework including four domains and 12 subdomains for assessing hospital resilience assessment in China [32-34]. This framework highlights managerial aspect of hospitals more than the structural and non-structural systems at the time of danger. Continuity of essential medical services as one of the domains of this framework only takes two factors, i.e. emergency medicine and surge capacity; whereas service continuity should include utility services, staff participation, and other similar fields as well [34]. In this framework, all the building elements have been mentioned as the architectural components and there is no distinction between the windows and doors with medical and laboratory equipment or electrical installations. Moreover, the financial supports of the hospital system has been neglected in the mentioned framework [33].

The idea of this study is to extract the relevant indicators which would be able to measure them quantitatively in the developed model for removing the weak points of qualitative models.

By considering all advantages and disadvantages of HDR surveyed models and tools, the indicators extracted from research studies in this systematic review were collected and categorized in Table 3. These indicators can be useful for assessing HDR.

Totally, the collected indicators were categorized in 3 domains, 27 subdomains, and relevant indicators that can be used for assessing HDR in future studies. The 


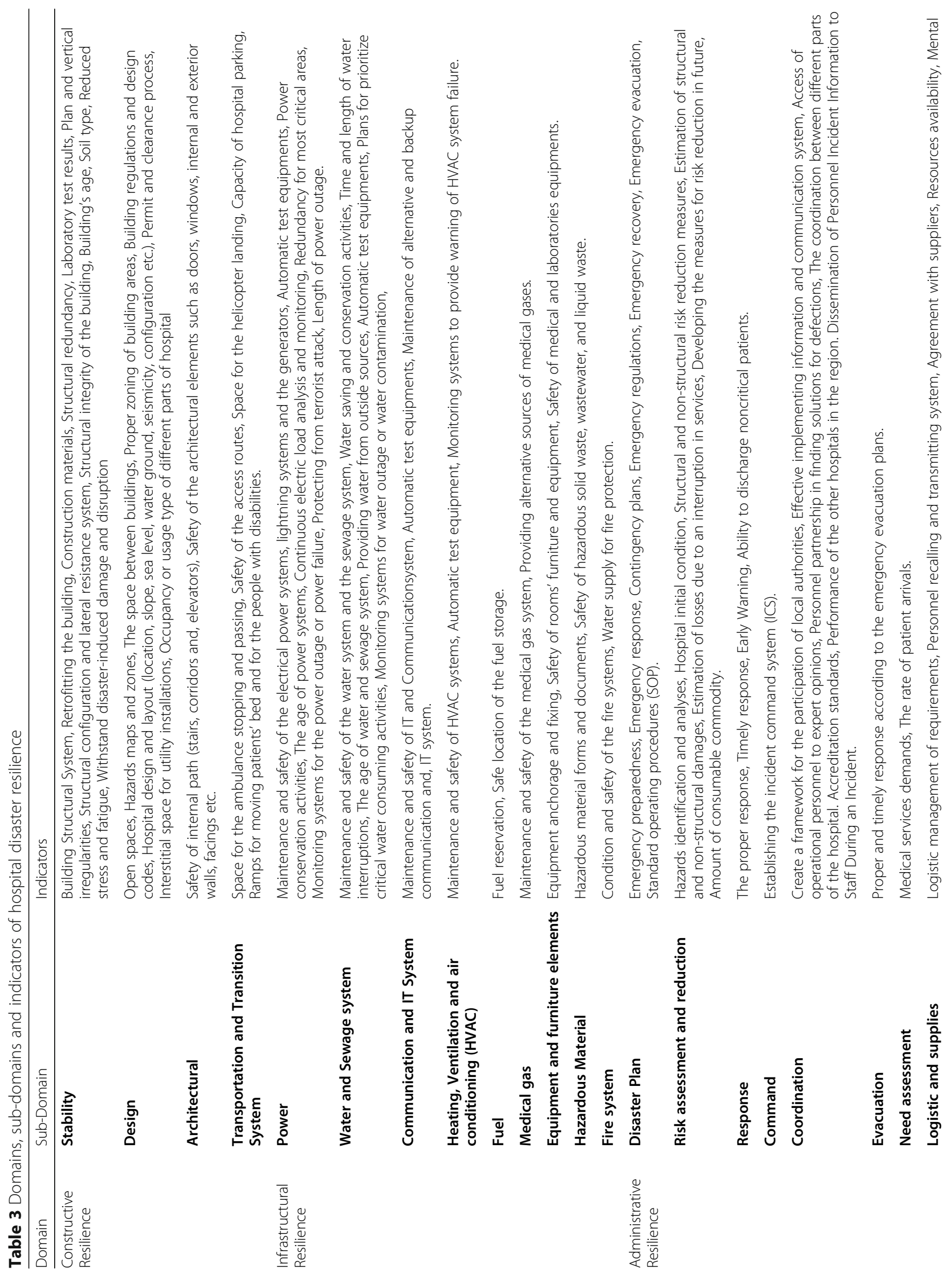




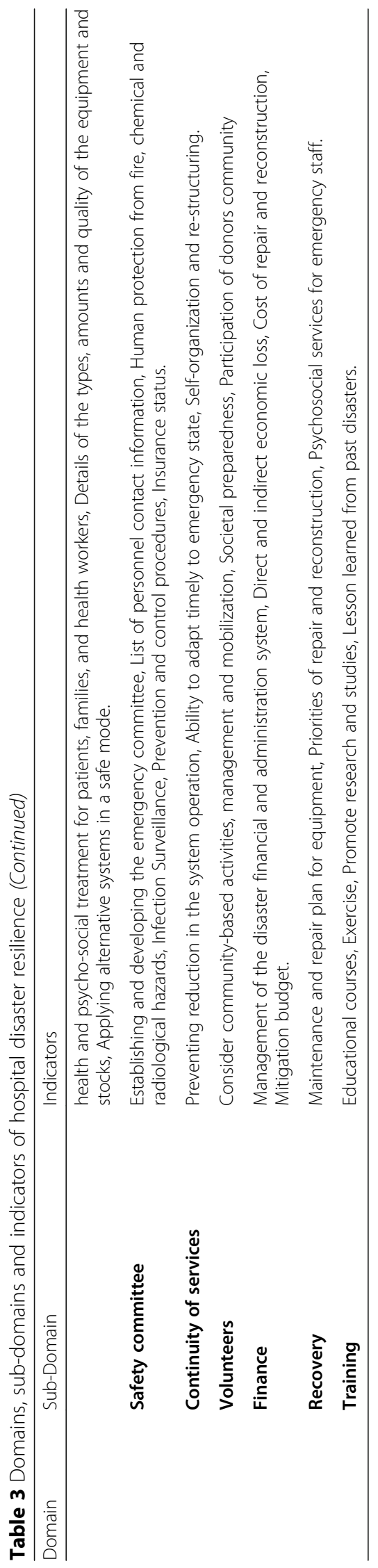


domains in Table 3were divided into three resilience types, including constructive, infrastructural, and administrative. Constructive resilience as a domain encompasses all elements of hospital building. This domain consists of architectural elements and the design of spaces and structures as subdomains for optimum function of hospitals to be inherently flexible, strong, and adaptive to emergency situation. Another subdomain is transportation and transmission that should be designed before the hospital construction and facilitates the access of patients and staff to the hospital. The infrastructural resilience consisted of non-structural elements which facilitate the hospital functions. The utilities and services, such as power, water or fire control were mentioned with their relevant indicators in this section. In addition, the protection of electrical utilities from terrorist and cyber-attacks was highlighted as a subdomain in the infrastructural resilience. The administrative resilience domain included activities for disaster management hospital, such as hazard and vulnerability reduction measures, preparedness, response, and recovery plans. In this domain, managing the volunteers is also a critical subdomain which shows the importance of the community-based activities as well as participatory approach of resilience. Due to the importance of repair and reconstruction of the structural and utility systems, the cost and priorities of these actions were mentioned as finance and recovery in the administrative resilience domain. Also, the domains and subdomains have the potential to substitute according to $4 \mathrm{R}$, including resourcefulness, redundancy, robustness, and rapidity. For instance, infrastructural resilience as a domain was categorized into the resourcefulness and redundancy as the resilience criteria demonstrate the hospital capability for mobilizing alternative external resources. It can also involve human resources and material in the process of recovery and also to substitute alternative elements. Constructive resilience is associated with robustness as another resilience criterion which shows the ability of hospital system to withstand a given level of shocks. Extracted indicators relevant to recovery and response are accounted as rapidity which is one of the resilience criteria reflecting the capacity of hospital system to meet priorities in order to recover functionality and avoid future disruption $[39,42,64]$.

\section{Limitations}

The main limitation of this review lies in the fact that English articlesand documents were only included. Therefore, the authorsmay have lost some of the relevant research studies which were in other languages. Furthermore, there were limited access to the full text of some papers that could affect finding comprehensive indicators. Identification and extracting indicators in some articles, especially in engineering fields, was difficult. Moreover, the number of extracted indicators wereconsiderably high that the authorshad to merge similar indicators.

\section{Conclusions}

This study highlighted the role of indicators and defined domains in order to assess hospital resilience through an integrated model. To do so, a set of domains, subdomains, and relevant indicators were extracted to be able to measure HDR quantitatively in future studies. The literature review proves that the functional safety has been an interested topic among scholars in order to increase the hospital resilience. However, hospital building and spaces as constructive resilience, also lifelines as infrastructural resilience,and importantly services as administrative resilience playsignificant role in hospital performance during disasters. Thesedomains and subdomains have beenignored in some studies. However, this studyrelies on the three mentioned resilience domains to focus onhospital resillience. Moreover, measuring HDR quantitatively is one of required factors suggested to be achieved in other studies as an important issue.

Further studies should be done to select other related indicators usingexpert judgement and improvement of the existing models. In addition, the validity of the model and indicators should be verified in further studies due togeneralizability in different countries and diverse hazards. These tools or models can help societies and government officials to reduce hospitals vulnerability and improve their performance and resilience against disasters.

\section{Supplementary information}

Supplementary information accompanies this paper at https://doi.org/10. 1186/s12913-020-4915-2.

Additional file 1. Database Search Strategy.

Additional file 2. Characteristics of the articles and other sources included in a systematic review of the literature.

\section{Abbreviations}

HDR: Hospital Disaster Resilience; HSI: Hospital Safety Index;

PRISMA: Preferred Reporting Items for Systematic Reviews and Meta-Analyses

\section{Acknowledgements}

We would like to appreciate Ali Jamshidi for editing and performing a critical review of the manuscript.

\section{Authors' contributions}

SF and AO conceptualized and designed the study, SF and FF carried out screening and extracting the data and prepared the manuscript. MM carried out quality assessment as third reviewer. $A O, B K$ and $A A$ supervised the study and provided critical comments. All authors read and approved the final manuscript.

Funding

The authors received no specific funding for this study. 


\section{Availability of data and materials}

The data supporting the conclusions in this article are available in the additional files. Data supporting study findings are available upon request.

\section{Ethics approval and consent to participate}

The Ethics Committee of Tehran University of Medical Sciences approved this study (IR.TUMS.SPH.REC.1397.155).

\section{Consent for publication}

Not applicable.

\section{Competing interests}

The authors declare that they have no competing interests.

\section{Author details}

'Department of Health in Emergencies and Disasters, School of Public Health, Tehran University of Medical Sciences, Tehran, Iran. ${ }^{2}$ Harvard Humanitarian Initiative, Harvard University, Cambridge, USA. ${ }^{3}$ Research Center for Health Services and Technologies, Semnan University of Medical Sciences, Semnan, Iran. ${ }^{4}$ Karlsruhe Institute of Technology (KIT), Center for Disaster Management and Risk Reduction Technology, Karlsruhe, Germany. ${ }^{5}$ Civil Engineering Department, Yazd University, Yazd, Iran.

Received: 16 July 2019 Accepted: 16 January 2020

Published online: 29 January 2020

\section{References}

1. Albanese J, Birnbaum M, Cannon C, Cappiello J, Chapman E, Paturas J, et al. Fostering disaster resilient communities across the globe through the incorporation of safe and resilient hospitals for community-integrated disaster responses. Prehosp Disaster Med. 2008;23(5):385-90.

2. Geroy LSA, Pesigan AM. Disaster risk reduction for health facilities in the Western Pacific region. Int J Disaster Resilience Built Environ. 2011;2(3):268-77.

3. Loosemore M, Chand A. Barriers to building resilience to extreme weather events in Australian hospitals. Proceedings of the 32nd Annual ARCOM Conference, ARCOM 2016; 2016.

4. Labarda C, Labarda MDP, Lamberte EE. Hospital resilience in the aftermath of typhoon Haiyan in the Philippines. Disaster Prev Manag Int J. 2017;26(4):424-36.

5. Krauskopf RB, Saavedra RR. Guidelines for vulnerability reduction in the design of new health facilities: Pan American health organization, Area on Emergency Preparedness and Disaster Relief; 2004.

6. Achour N, Pascale F, Price ADF, Polverino F, Aciksari K, Miyajima M, et al. Learning lessons from the 2011 Van earthquake to enhance healthcare surge capacity in Turkey. Environ Hazards-Human Policy Dimen. 2016;15(1):74-94.

7. Hall ML, Lee AC, Cartwright C, Marahatta S, Karki J, Simkhada P. The 2015 Nepal earthquake disaster: lessons learned one year on. Public Health. 2017; 145:39-44.

8. Jacques CC, McIntosh J, Giovinazzi S, Kirsch TD, Wilson T, Mitrani-Reiser J. Resilience of the Canterbury hospital system to the 2011 Christchurch earthquake. Earthquake Spectra. 2014;30(1):533-54.

9. Koshimura S, Shuto N. Response to the 2011 Great East Japan Earthquake and Tsunami disaster. Philos Trans A Math Phys Eng Sci. 2015;373(2053). https://doi.org/10.1098/rsta.2014.0373.

10. Yusoff N, Shafii H, Omar R, editors. The impact of floods in hospital and mitigation measures: A literature review. Materials Science and Engineering Conference Series. Johor Bahru; 2017.

11. Razzaghi S, Ghafory-Ashtiany M. A preliminary reconnaissance report on August 11th 2012. Varzaghan-Ahar Twin Earthquakes in NW of Iran; 2012.

12. Ahmadi A, Bazargan-Hejazi S. 2017 Kermanshah earthquake; lessons learned. J Inju Violence Res. 2018;10(1):1.

13. Jafar E, Taneja U. Business continuity planning - a survey of hospitals in Delhi. J Public Health. 2017;25(6):699-709.

14. Achour N, Price ADF. Resilience strategies of healthcare facilities: present and future. Int J Disaster Resilience Built Environ. 2010;1(3):264-76.

15. Achour N, Price ADF. Healthcare resilience to natural hazards: an achievable target. Int J Disaster Resilience Built Environ. 2011;2(3):45-56.

16. ISDR U. Hyogo framework for action 2005-2015: building the resilience of nations and communities to disasters. Extract from the final report of the
World Conference on Disaster Reduction (A/CONF 206/6). Geneva: The United Nations International Strategy for Disaster Reduction; 2005.

17. UNISDR U. Sendai framework for disaster risk reduction 2015-2030. Sendai: Proceedings of the 3rd United Nations World Conference on DRR; 2015.

18. Bruneau M, Chang SE, Eguchi RT, Lee GC, O'Rourke TD, Reinhorn AM, et al. A framework to quantitatively assess and enhance the seismic resilience of communities. Earthquake Spectra. 2003;19(4):733-52.

19. Ostadtaghizadeh A, Ardalan A, Paton D, Jabbari H, Khankeh HR. Community disaster resilience: a systematic review on assessment models and tools. PLoS currents. 2015;7. https://doi.org/10.1371/currents. dis.f224ef8efbdfcf1d508dd0de4d8210ed.

20. Olu O. Resilient health system as conceptual framework for strengthening public health disaster risk management: an African viewpoint. Front Public Health. 2017:5:263.

21. Guillemot J. Operational framework for building climate resilient health systems; 2015.

22. Ardalan A, Keleh MK, Saberinia A, Khorasani-Zavareh D, Khankeh H, Miadfar J, et al. 2015 estimation of hospitals safety from disasters in IR Iran: the results from the assessment of 421 hospitals. PLoS One. 2016;11(9):e0161542.

23. Brankov B, Nenković-Riznić M, Pucar M, Petrović S. Hospital safety in spatial and urban planning and design-seismic zone in the Kolubara region in Serbia. Proceedings of Seismic and Energy Renovation for Sustainable Cities: SER4SC; 2018. p. 82-91.

24. Djalali A, Ardalan A, Ohlen G, Ingrassia PL, Della Corte F, Castren M, et al. Nonstructural safety of hospitals for disasters: a comparison between two capital cities. Disaster Med Public Health Prep. 2014;8(2):179-84.

25. Mulyasari F, Inoue S, Prashar S, Isayama K, Basu M, Srivastava N, et al. Disaster preparedness: looking through the lens of hospitals in Japan. Int J Disaster Risk Sci. 2013;4(2):89-100.

26. Pisla M, Domente D, Chetraru L, Ostaficiuc R. Evaluation of hospital safety in the Republic of Moldova. Chsiinau: Republican Center for Disaster Medicine; 2010.

27. World Health Organization. Hospital safety index: Guide for evaluators, 2 edn. Geneva: World Health Organization; 2015.

28. Aguirre BR, Dynes R, Kendra J, Connell R. Institutional Resilience and Disaster Planning for New Hazards: Insights from Hospitals. J Homel Secur Emerg Manag. 2005;2(2):1-17.

29. Dobalian A, Stein JA, Radcliff TA, Riopelle D, Brewster P, Hagigi F, et al. Developing valid measures of emergency management capabilities within US Department of veterans affairs hospitals. Prehosp Disaster Med. 2016; 31(5):475-84.

30. Park I, Sharman R, Rao HR. Disaster experience and hospital information systems: an examination of perceived information assurance, risk, resilience, and his usefulness. MIS Q. 2015;39(2):317-44.

31. Shirali GA, Azadian S, Saki A. A new framework for assessing hospital crisis management based on resilience engineering approach. Work. 2016;54(2): 435-44.

32. Zhong S, Clark M, Hou XY, Zang Y, FitzGerald G. Development of key indicators of hospital resilience: a modified Delphi study. J Health Serv Res Policy. 2015;20(2):74-82.

33. Zhong S, Clark M, Hou XY, Zang YL, Fitzgerald G. Development of hospital disaster resilience: conceptual framework and potential measurement. Emerg Med J : EMJ. 2014;31(11):930-8.

34. Zhong S. Developing an evaluation framework for hospital disaster resilience: tertiary hospitals of Shandong province. China: Queensland University of Technology; 2014.

35. (FEMA) FEMA. Design Guide for Improving Hospital Safety in Earthquakes, Floods, and High Winds: Providing Protection to People and Buildings (FEMA 577). 2007

36. (HBN) HBN. Planning for a resilient healthcare estate. 2014.

37. (WHO) WHO.Hospitals Safe from Disasters: Reduce Risk, Protect Health Facilities, Save Lives. United Nations International Strategy for Disaster Reduction (UNISDR); 2007.

38. Achour N, Miyajima M, Pascale F, Price ADF. Hospital resilience to natural hazards: classification and performance of utilities. Disaster Prev Manag Int J. 2014;23(1):40-52.

39. Barror RF, Gardner RJ. USPHS: building resilience. Mil Eng. 2008; 100(653):83-5.

40. Bruneau M, Reinhorn A. Exploring the concept of seismic resilience for acute care facilities. Earthquake Spectra. 2007;23(1):41-62.

41. Chow WW, Loosemore M, McDonnell G. Modelling the impact of extreme weather events on hospital facilities management using a system dynamics 
approach. Association of Researchers in Construction Management, ARCOM 2012 - Proceedings of the 28th Annual Conference; 2012.

42. Cimellaro GP, Reinhorn AM, Bruneau M. Seismic resilience of a hospital system. Struct Infrastruct Eng. 2010;6(1-2):127-44.

43. Cimellaro GP, Reinhorn AM, Bruneau M. Framework for analytical quantification of disaster resilience. Eng Struct. 2010;32(11):3639-49.

44. Hassan E, Mahmoud H, editors. Resilience Quantification of a Steel Hospital Subjected to Earthquake. In: 11th United States National Conference on Earthquake Engineering. USA; 2018.

45. Khanmohammadi S, Farahmand H, Kashani H. A system dynamics approach to the seismic resilience enhancement of hospitals. Int J Disaster Risk Reduction. 2018;31:220-33.

46. Lane SJ, McGrady E. Measures of emergency preparedness contributing to nursing home resilience. J Gerontol Soc Work. 2018;61(7):751-74.

47. Masko ML, Eckert CM, Caldwell NH, Clarkson PJ. Designing for resilience: using a Delphi study to identify resilience issues for hospital designs in a changing climate. DS 68-5: Proceedings of the 18th International Conference on Engineering Design (ICED 11), Impacting Society through Engineering Design, vol. 5. Denmark: Design for X/Design to X, Lyngby/Copenhagen; 2011. p. 15-1908. 2011

48. McDaniels T, Chang S, Cole D, Mikawoz J, Longstaff H. Fostering resilience to extreme events within infrastructure systems: characterizing decision contexts for mitigation and adaptation. Glob Environ Chang. 2008;18(2):310-8.

49. Norazam AS. Resilient Health Infrastructure: Strengthening hospitals' capacity to respond effectively during disasters and crises; 2018.

50. Paterson J, Berry P, Ebi K, Varangu L. Health care facilities resilient to climate change impacts. Int J Environ Res Public Health. 2014;11(12):13097-116.

51. Prudenzi A, Fioravanti A, Caracciolo V. Resilient power in hospitals: The S. Giovanni addolorata general hospital case study; 2017.

52. Rodriguez-Llanes J, Deeming H, McLean L, Castro Delgado R, M'Bala S, van Loenhout J, et al. Handbook: data-collection protocols and statistical analysis plan for emBRACE HSS component2015.

53. Samsuddin NM, Takim R, Nawawi AH, SNA SA. Disaster Preparedness Attributes and Hospital's Resilience in Malaysia; 2018.

54. Sternberg E. Planning for resilience in hospital internal disaster. Prehosp Disaster Med. 2003;18(4):291-300

55. Takim R, Samsuddin NM, Nawawi AH. Assessing The Content Validity Of Hospital Disaster Resilience Assessment Instrument. Jurnal Teknologi. 2016;78(5-2):35-42.

56. Toner ES, McGinty M, Schoch-Spana M, Rose DA, Watson M, Echols E, et al. A community checklist for health sector resilience informed by hurricane Sandy. Health Security. 2017;15(1):53-69.

57. Valcárcel J, Pujades L, Barbat A, Mora M, Cardona O. Integrated evaluation of hospital safety: implications on resilience and welfare of communities. 14th European Conference on Earthquake Engineering; 2010

58. Vugrin ED, Verzi SJ, Finley PD, Turnquist MA, Griffin AR, Ricci KA, et al. Modeling hospitals' adaptive capacity during a loss of infrastructure services. J Healthcare Eng. 2015;6(1):85-120.

59. Zhong S, Clark M, Hou XY, Zang YL, Fitzgerald G. Proposing and developing a definition and conceptual framework for health care resilience to cope with disasters. Emergencias. 2014;26(1):69-77.

60. Organization WH. Safe hospitals in emergencies and disasters: structural, non-structural and functional indicators. Manila: WHO Regional Office for the Western Pacific; 2010.

61. Zhong S, Hou XY, Clark M, Zang YL, Wang L, Xu LZ, et al. Disaster resilience in tertiary hospitals: a cross-sectional survey in Shandong Province, China. BMC Health Serv Res. 2014;14:135.

62. Azadian S, Shirali GA, Saki A. Reliability and validity of assessment of crisis management questionnaire based on seven principles of resilience engineering approach in hospitals. Iran Occupational Health. 2016;13(1):15-26.

63. Aguirre B, Dynes RR, Kendra J, Connell R. Institutional resiliance and disaster planning for new hazards: insights from hospitals. J Homeland Sec Emerg Manag. 2005;2.

64. Cimellaro GP, Reinhorn AM, Bruneau M. OK framework for analytical quantification of disaster resilience. Eng Struct. 2010;32(11):3639-49.

65. Preparedness PAHOE, Program DRC. Principles of disaster mitigation in health facilities: Pan American health org; 2000.
66. Maurice P, Lavoie M, Laflamme L, Svanström L, Romer C, Anderson R. Safety and safety promotion: definitions for operational developments. Inj Control Saf Promot. 2001;8(4):237-40.

67. Norris F H, Stevens S P, Pfefferbaum B, Wyche K, Pfefferbaum R L. community resilience as a metaphor, theory, set of capacities, and strategy for disaster readiness. Am J Community Psychol. 2008:41:127-50.

68. Ostadtaghizadeh A, Ardalan A, Paton D, Khankeh H, Jabbari H. Community disaster resilience: a qualitative study on Iranian concepts and indicators. Nat Hazards. 2016;83(3):1843-61.

\section{Publisher's Note}

Springer Nature remains neutral with regard to jurisdictional claims in published maps and institutional affiliations.
Ready to submit your research? Choose BMC and benefit from:

- fast, convenient online submission

- thorough peer review by experienced researchers in your field

- rapid publication on acceptance

- support for research data, including large and complex data types

- gold Open Access which fosters wider collaboration and increased citations

- maximum visibility for your research: over $100 \mathrm{M}$ website views per year

At BMC, research is always in progress.

Learn more biomedcentral.com/submissions 